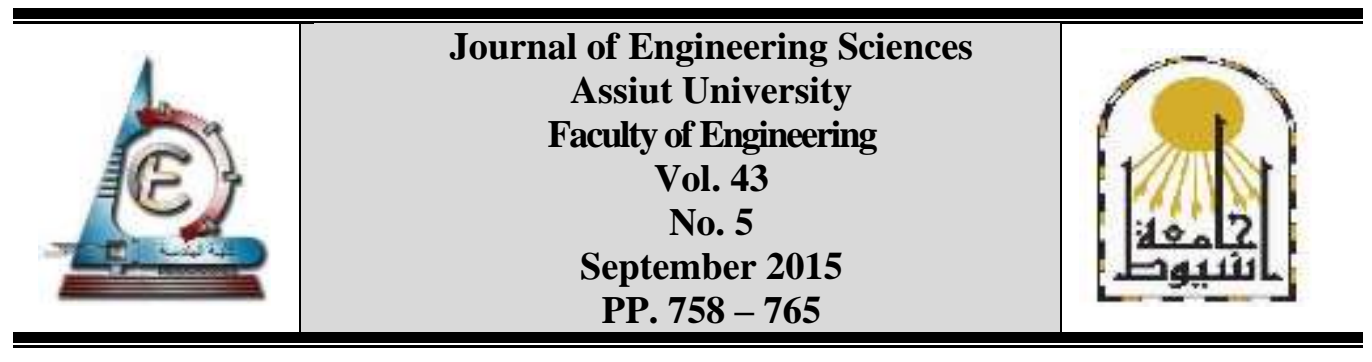

\title{
THE EFFECTIVENESS OF DIFFERENT CONFIGURATIONS OF VERTICAL LOUVERS ON ENERGY PERFORMANCE IN OFFICE BUILDINGS IN CAIRO
}

\author{
Ahmed Atef Faggal \\ Architectural Department, Faculty of Engineering, Ain Shams University, Cairo, Egypt.
}

(Received 5 August 2015; Revised 28 August 2015; Accepted 10 September 2015)

\begin{abstract}
This paper aims to identify the effect of solar control devices - vertical sun louvers - in an open-plan office space with a western full glazing facade in order to test the optimization level of energy performance within office buildings in Cairo through controlling the different configurations of the vertical louvers. An action experimental research is used to investigate annual cooling loads (representing energy performance).

Environmental simulation software (Design Builder for thermal and energy + for analysis) are used during this testing research to investigate the effect of changing rotation angle of vertical louvers on annual cooling loads. It is concluded that energy performance can be enhanced while applying small and large values of rotation angles of vertical louvers.
\end{abstract}

Keywords: Dynamic thermal simulation, Thermal performance, Sustainable design, Green buildings

\section{Introduction}

Energy consumption, as a critical issue, most probably is neglected by architects and designers in the early stages of the design process. Office buildings suffer the same negligence regarding the performance; designers focus on the aesthetic aspects trying to please the client, paying no attention to the environmental issues. The transparent façade is a dominant feature in office buildings. Thus, the excessive cooling load is the common feature in office buildings that are located in desert environments. Adopting the energy conscious approach from the very beginning impose thinking is a more holistic approach.

Studying the optimization configuration is not only for the sake of energy conservation, but also for its positive impact on human health and the wellbeing. As per that, many researches were concerned with the study of the correlation between human comfort, productivity, rate of absenteeism and staff errors.

Also, number of researches has discussed the performance of energy conservation through the use of solar control devices. A paper by (Gadelhak, et. al., 2012) [2] has studied the effect of different configurations and settings of sun breakers on the visual and thermal performance of a south oriented office spaces. Another paper by (Alzoubi and Alzoubi, 2010) [3] has examined the effect of horizontal and vertical shading devices on southern 
façade and ended up with the optimum orientation for both illuminance and energy targets. A.A. Ahmed (2012) [1] has studied the influence of different depths of vertical shading devices in different orientations on the thermal performance in residential buildings.

This paper aims to identify the effect of solar control devices - vertical sun louvers - in an open-plan office space with a western full glazing façade on the indoor energy performance.

\subsection{Problem definition}

The enhancements in Architectural aesthetic features may lead to overheat gain/storage that sequentially causes extra indoor cooling loads. So, the question may be formulated as: what is the optimum configuration of a specific treatment (vertical louvers) to elevate energy performance inside office spaces?

The choice of Office spaces is generated from the large amount of energy consumed in the office spaces due to the cooling loads required during day time to achieve indoor thermal comfort which affect directly on the general energy loads consumed in the city.

\subsection{Main goal}

Enhancement and optimization of energy performance within office buildings in Cairo through controlling the different configurations of the vertical louvers.

\subsection{Operation variables}

\section{A- Dependent variables:}

- Energy performance (represented by generated cooling loads -kWh-)

\section{$B$-Independent variables:}

- Rotation angle of vertical louvers.

\section{C-Controlled variables:}

Many elements can be classified as controlled variables:

- Building orientation

- Window to wall ratio

- Season of testing
- Office space dimensions

- Glazing material specifications [5]

\section{Research methodology}

Action experimental research will be used as a research methodology to investigate annual cooling loads (representing energy performance). Environmental simulation software (Design Builder for thermal and energy + for analysis) will be used during this testing research to investigate the effect of changing rotation angle and depth of vertical louvers on annual cooling loads.

This empirical testing will track simulation results through testing the effect of different rotation angles of vertical louvers on annual cooling loads.

\subsection{Design builder results validation}

Design Builder provides a graphical user interface to the Energy Plus simulation engine. It is developed to be used in all design stages. Version-2.4.2.015 was used for this analysis. Although Design Builder is based on a complex simulation program, it attempts 
Ahmed Atef Faggal, The effectiveness of different configurations of vertical louvers on energy ...

to address the architect's specific language by a visual oriented interface and inputs in different levels of detail. Nevertheless, the output constitutes one of the major limitations concerning architect-friendliness. The parametric analyses on the other hand, could provide useful information to support architects in the design of NZEB. [6]

\subsection{Design builder accuracy (High)}

The tools' analysis engine used is Energy Plus. Energy Plus has been widely reviewed and validated using the ASHRAE/BESTEST evaluation protocol; the results in all the test buildings fell within the acceptance range as illustrated in figure (1) (ANSI/ASHRAE Standard 140-2001). [6]

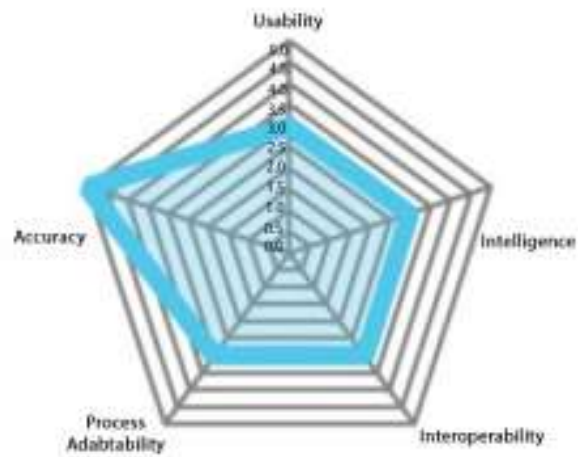

Fig. 1. Results of the NZEB Tools Mechanics

\subsection{Setting}

A typical open-plan office space was selected to be investigated. Waterway administration compound in $5^{\text {th }}$ settlement, New Cairo, shown in figure (2), was selected to represent typical office units in Cairo. The project is located in Cairo $\left(30^{\circ} \mathrm{N}-31^{\circ} \mathrm{E}\right)$ that is characterized by its desert environment and clear sky condition. The project is under construction, so only minor modifications on facade design and louvers setting will be available. Only factors of rotation angle and depth of sun breakers are selected to be changed.

Figure (3) shows master plan and floor plan of Building B that contains the office space under investigation which has single exposed curtain wall facade. The facade under investigation is oriented towards the west with vertical louvers of depth $1.00 \mathrm{~m}$ forming the base case as illustrated in details within figure (3) and table (1).

\section{Experimentation design}

Different louvers configurations were investigated for analyzing the thermal performance. Evaluating the results has been done according to two sequential phases. Investigation was dedicated for testing ten cases -besides the base case- of different rotation angles of louvers, as shown in figure (4), and its impact on the annual cooling loads $(\mathrm{kWh})$ inside the space.

\subsection{Vertical louvers rotation angles}

This experimentation aims to investigate the energy performance of the different cases of rotation angles on the year round as illustrated in figure (5). The occupied schedule used for this office space is from 8:00am till 6:00pm. 

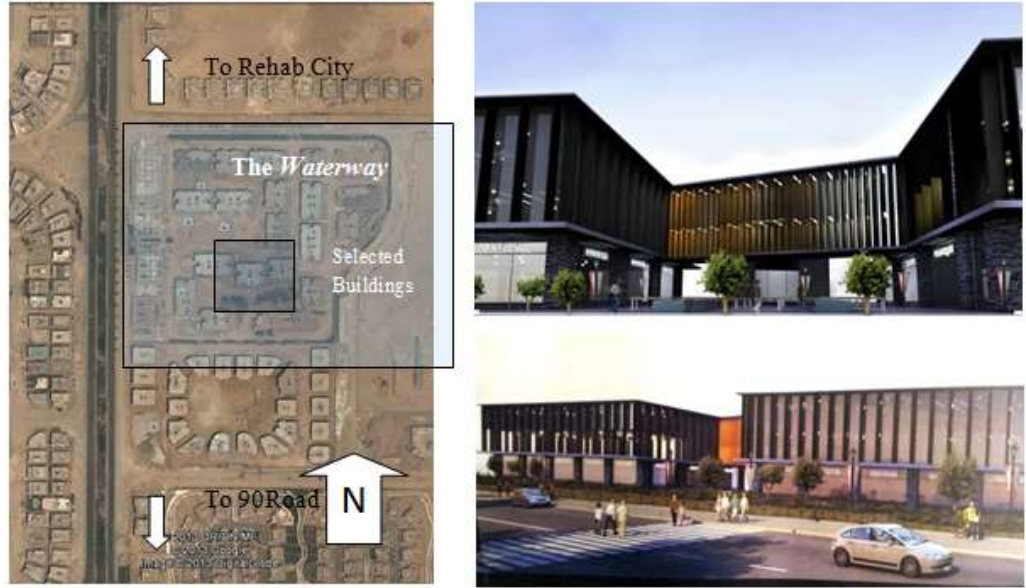

Fig. 2. Waterway office buildings project, 5th Settlement, New Cairo
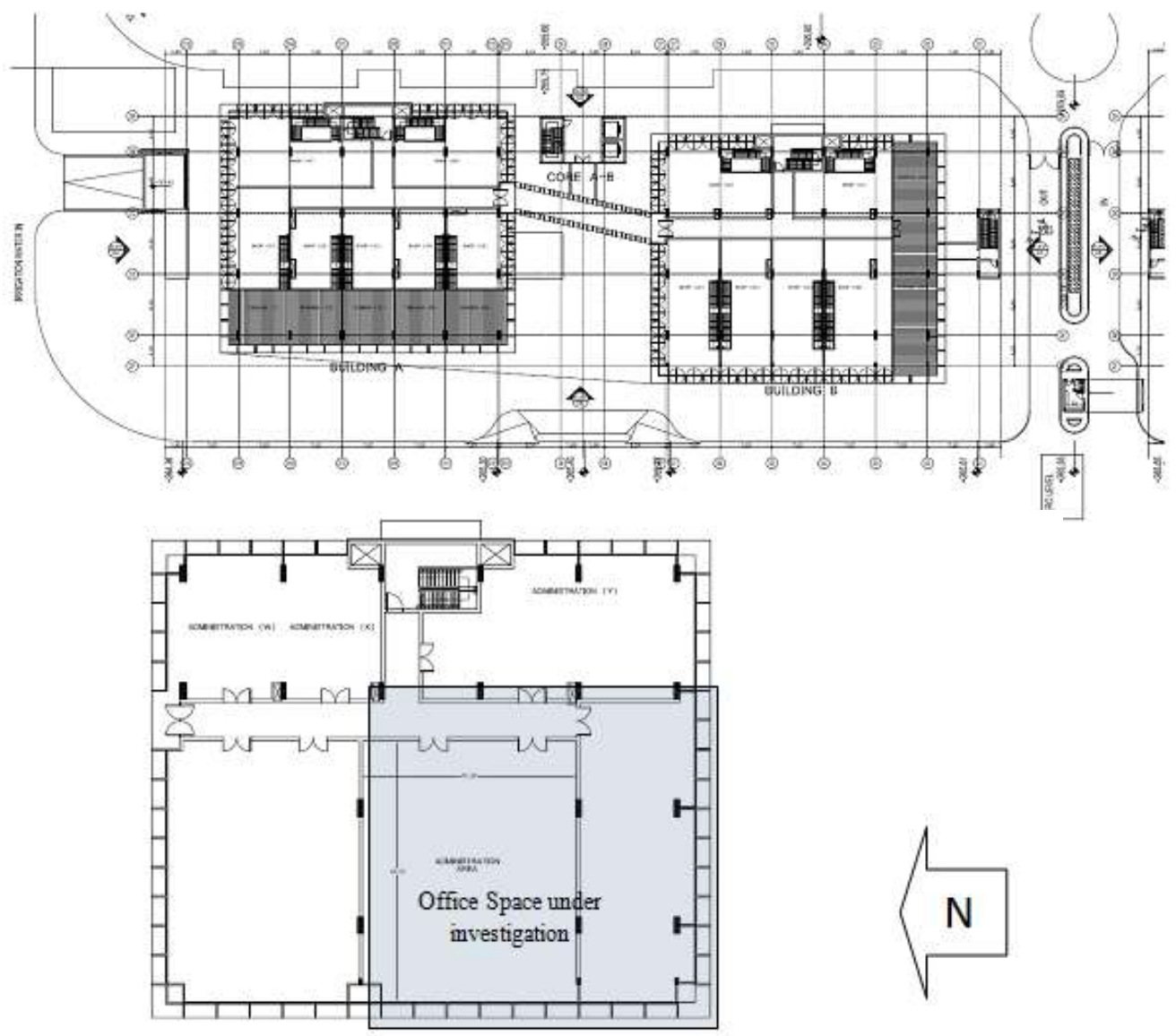

Fig. 3. Master plan and floor plan of waterway office building, showing office space under investigation 

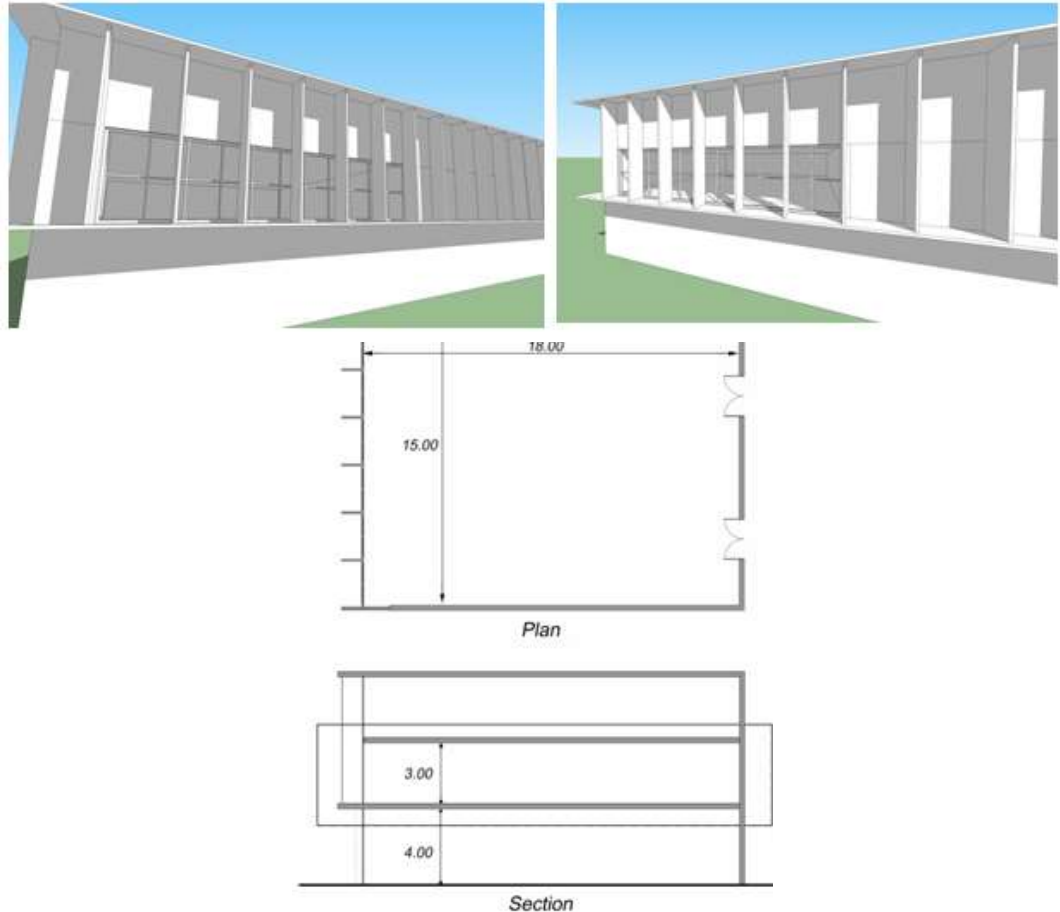

Fig. 4. Base Case architectural drawings

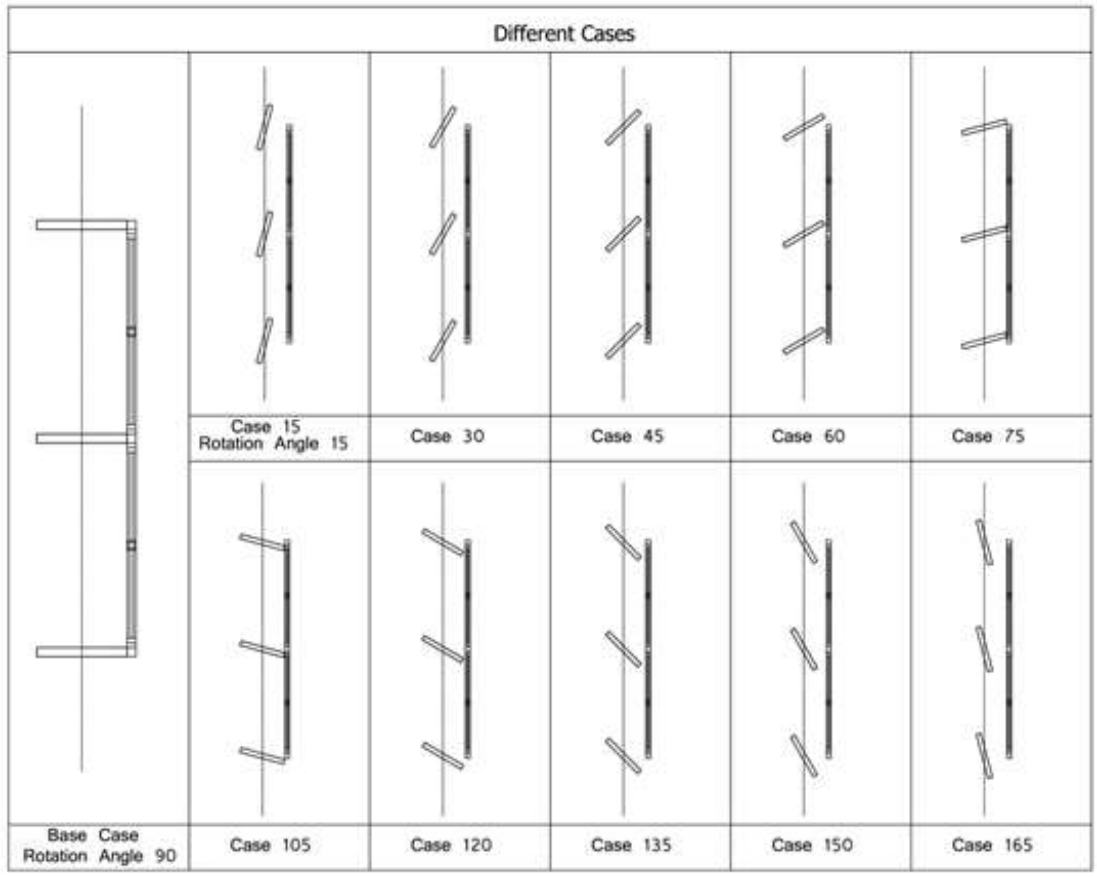

Fig. 5. Rotation Angle for the Alternatives 
Table 1.

Detailed dimensions and parameters of the office space (Base Case)

\begin{tabular}{|c|c|c|}
\hline \multicolumn{3}{|c|}{ Space Parameters } \\
\hline \multicolumn{2}{|c|}{ Floor Level } & $1^{\text {st }}$ floor $(+4.00 \mathrm{~m})$ \\
\hline \multicolumn{2}{|c|}{ Dimensions (m) } & $18.00 * 15.00 * 3.00$ \\
\hline \multicolumn{3}{|c|}{ Internal surfaces } \\
\hline \multirow[t]{2}{*}{ Walls } & Reflectance & $50 \%$ \\
\hline & Material & Medium colored walls-Off-white \\
\hline \multirow[t]{2}{*}{ Ceiling } & Reflectance & $80 \%$ \\
\hline & Material & White colored ceiling \\
\hline \multirow[t]{2}{*}{ Floor } & Reflectance & $20 \%$ \\
\hline & Material & Wooden floor \\
\hline \multicolumn{3}{|c|}{ Façade Parameters } \\
\hline \multirow{2}{*}{$\begin{array}{l}\text { West } \\
\text { facade }\end{array}$} & Dimensions $(\mathrm{m})$ & $14.00 * 3.00$ \\
\hline & Glazing & Double panel clear glass \\
\hline \multirow[t]{2}{*}{ Louvers } & $\begin{array}{l}\text { Dimensions(m) } \\
\text { Depth*Thickness }\end{array}$ & $1.00 * 0.10$ \\
\hline & Reflectance & $50 \%$ \\
\hline
\end{tabular}

\subsection{Thermal and energy analysis}

Design Builder simulation software, with Energy Plus as an engine, is used for energy performance simulations. ETMY weather data filing system is used as an engine weather data for Cairo. Table (2) shows the Energy Plus simulation parameters. Annual energy simulations were conducted to all cases.

Table 2.

Energy plus simulation parameters

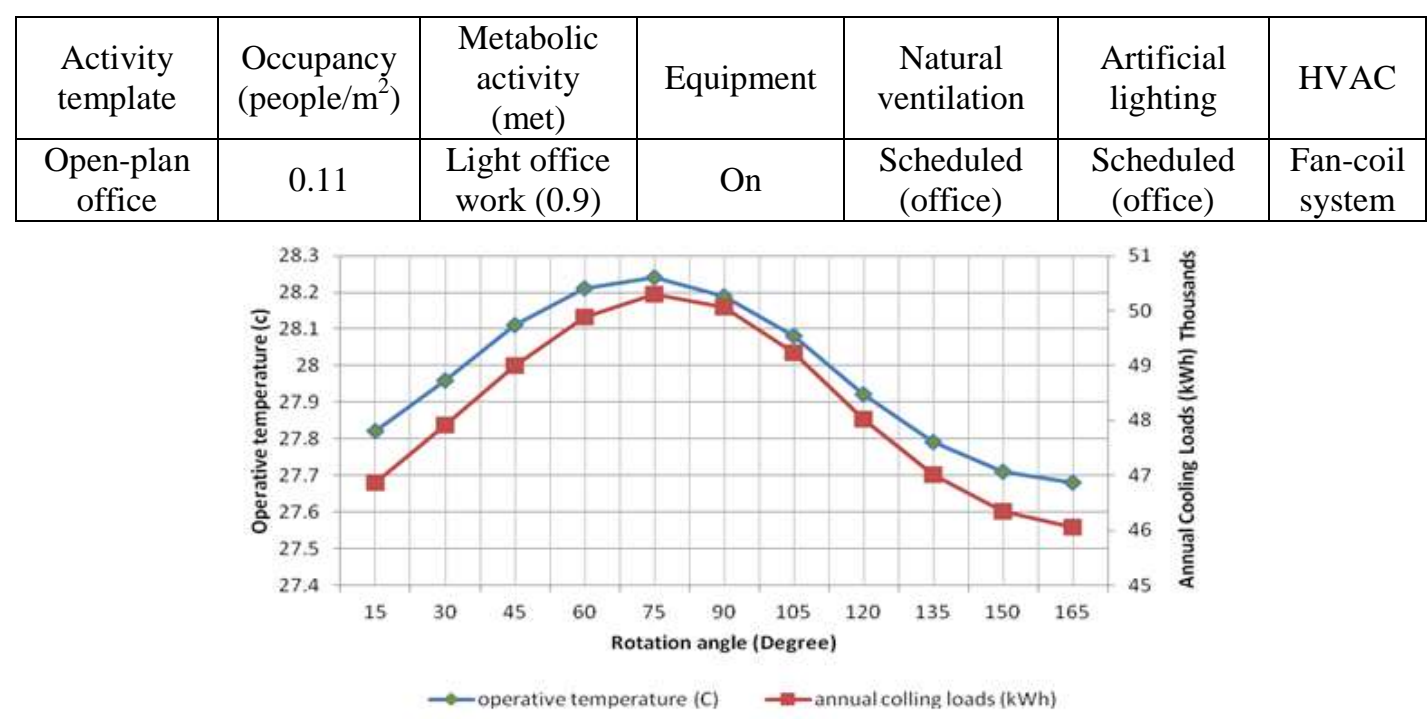

Fig. 6. Thermal (operative temperature) and Energy (annual cooling loads) analysis for different rotation angles 
Ahmed Atef Faggal, The effectiveness of different configurations of vertical louvers on energy ...

\subsection{Simulation results}

\subsubsection{Results of thermal and energy analysis}

Operative temperature is used to represent the indoor thermal behavior. As shown in figure (6), the difference between maximum and minimum values of mean annual operative temperature due to changing angle of rotation is around only $\left(\mathbf{0 . 6 0}^{\circ} \mathbf{C}\right)$. But it was reflected in energy consumption by around $(4000 \mathrm{kWh})$ between maximum and minimum values of annual cooling loads.

\section{Conclusion and Recommendations}

\subsection{Conclusion}

- It is concluded that the cases of $(15,135,150$ and 165) in rotation angle achieve the most energy conservation between $(3000$ to $4000 \mathrm{kWh})$ less than the base case $\left(90^{\circ}\right)$.

- While modifying louvers configurations, maximum reduction in cooling loads was a value of nearly $(4500 \mathrm{kWh})$.

- From graphs, it can be concluded that energy performance can be enhanced while applying small and large values of rotation angles of vertical louvers.

- The research was for an annual investigation regardless specific seasonal requirements. So specific seasonal treatment or different configurations due to season may lead to larger optimization in energy performance.

\subsection{Recommendations}

- In compatible with the previous conclusion, smart solutions using automatic / motorized shading devices will be effective in managing the louvers multiconfigurations due to season/time.

- Regarding indoor Day lighting levels [4], effective different configurations of vertical louvers rotation angles might not reach the acceptable daylighting levels. So, investigation the effectiveness of different configurations of vertical louvers on both energy performance and day lighting levels is a vital further action.

\section{REFERENCES}

[1] Ahmed, A. A. (2012). Using simulation for studying the influence of vertical shading devices on the thermal performance of residential buildings (Case study: New Assiut City). Ain Shams Engineering Journal , 163 - 174.

[2] Gadelhak, M., et. al. (2012), "High performance facades: The effect of sun breakers on daylighting performance and energy consumption in south oriented office spaces", Egypt

[3] Alzoubi, H and Alzoubi, A., (2010), "Assessment of building façade performance in terms of daylighting and the associated energy consumption in architectural spaces: Vertical and horizontal shading devices for southern exposure facades" Energy Conversion and Management, no.t 5, p. 1592-1599.

[4] Sabry, H., et. al. (2012), "Utilization of Combined Daylighting Techniques for Enhancement of Natural Lighting Distribution in Clear-Sky Residential Desert Buildings", PLEA2012- $28^{\text {th }}$ Conference, towards an environmentally responsible architecture, Lima, Peru.

[5] IESNA, illuminating Engineering Society of North America(2000), "IESNA Lighting Handbook, $9^{\text {th }}$ ed.

[6] Attia Shady, "State of the Art of Existing Early Design Simulation Tools for Net Zero Energy Buildings: A Comparison of Ten Tools", Université catholique de Louvain, Louvain La Neuve, Belgium, March 2011 


\section{تأثثير عدة أشكال مختلفة من كاسرات الثشمس الرأسية على أداء الطاقة في المباني الإدارية بالقاهرة}

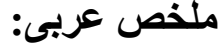

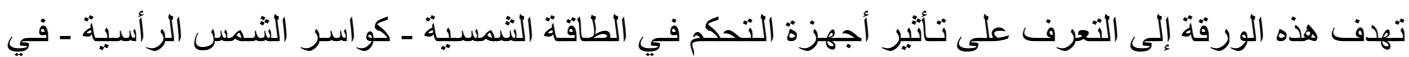

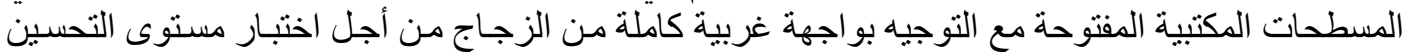

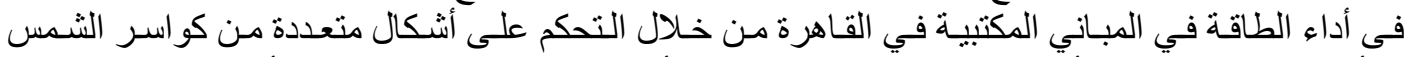

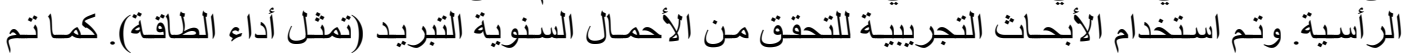

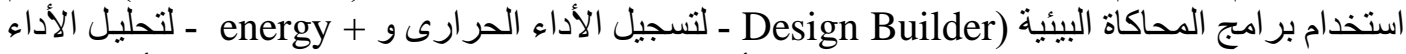

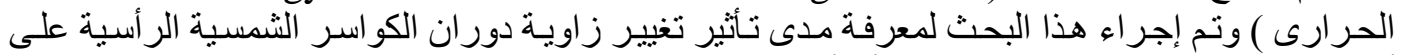

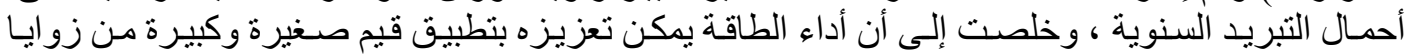

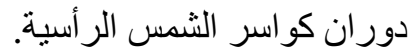

